\title{
EFEKTIFITAS PELATIHAN KADER KESEHATAN DALAM PENANGANAN TUBERKULOSIS DI WILAYAH BINAAN
}

\section{Elman Boy}

Departemen IImu Kesehatan Masyarakat, Fakultas Kedokteran Universitas Muhammadiyah Sumatera Utara

\section{ABSTRACT}

Background: Medan is an area with the largest TB patients in the North Sumatra Province. Since 2014, Medan Denai Distric is a target area of Medical Faculty of University Muhammadiyah North Sumatra (FM UMSU). One of the implemented program is formulating a Community Forum on TB Care. The objective of this study is to find out the effectiveness of TB management training by improving the knowledge of health cadres.

Method: This was a one-group pre test-and post-test design. Participants of the research were all the TB care Forum members that was selected by inclusive criterias. Data collection was conducted by using quesionnaires of knowledge. Data analysis used Wilcoxon test with significancy level $=0,05$.

Results: The cadres knowledge significantly rise after the TB management training.

Conclusion: TB management training for health cadre was effective in improving knowledge of health cadre.

Keywords: training, tuberculosis, TB, health cadre

\section{ABSTRAK}

Pendahuluan: Medan merupakan daerah dengan jumlah pasien TB terbanyak di propinsi Sumatera Utara. Sejak tahun 2014, Kecamatan Medan Denai telah menjadi area target Fakultas Kedokteran Universitas Muhammadiyah Sumatera Utara (FK UMSU) dalam salah satu program yang diimplementasikan, yakni menyusun forum komunitas peduli TB. Tujuan dari penelitian ini adalah untuk menilai keefektifan pelatihan manajemen TB dengan meningkatkan pengetahuan kesehatan para kader.

Metode: Penelitian ini menggunakan desain one-group pretest-and posttest design. Subyek penelitian adalah seluruh anggota Forum Peduli TB yang dipilih dengan kriteria inklusi. Pengumpulan data dilakukan dengan menggunakan kuesioner pengetahuan. Analisis data menggunakan uji Wilcoxon dengan tingkat signifikansi $=0,05$.

Hasil: Pengetahuan kader kesehatan meningkat secara signifikan setelah dilaksanakannya pelatihan manajemen TB

Kesimpulan: Pelatihan manajemen TB bagi para kader kesehatan efektif meningkatkan pengetahuan pada kader kesehatan.

Kata kunci: pelatihan, tuberkulosis, TB, kader kesehatan

\section{PENDAHULUAN}

Tuberkulosis (TB) adalah penyakit menular yang disebabkan oleh bakteri (Mycobacterium tuberculosis). Penyakit ini telah menyumbangkan angka kematian tertinggi kedua setelah HIV/AIDS di dunia ini. ${ }^{1}$
Pada tahun 2013 saja, Badan Kesehatan Dunia (WHO) melaporkan satu setengah juta orang di dunia meninggal dunia oleh karena TB. ${ }^{1}$ Sementara itu ada sembilan juta orang yang tengah terinfeksi TB di seluruh dunia. ${ }^{1}$ Lebih dari 95\% kematian akibat

korespondensi: dokterelman@gmail.com 
penyakit $\mathrm{TB}$ ini terjadi di negara-negara dengan tingkat ekonomi menengah ke bawah termasuk Indonesia. ${ }^{1}$ Dari data yang ada, TB juga menjadi penyumbang lima besar penyebab kematian pada wanita berusia 15-44 tahun. ${ }^{1}$ Diperkirakan sebanyak 550 ribu anak di dunia telah terjangkit penyakit TB dan sekitar 80 ribu diantaranya telah meninggal dunia oleh karena penyakit ini. ${ }^{1}$ Data menunjukkan angka kematian pada penderita TB dengan HIV positif menjadi lebih tinggi yaitu seperempat kematian terjadi dari seluruh kasus. Sementara itu kasus TB multi-drug resistant (TB MDR) masih terus terjadi, saat ini secara global diperkirakan ada sekitar 480 ribu kasus TB MDR. ${ }^{1}$

Dengan demikian dunia terus berupaya secara sistematis dan bekerjasama dalam menanggulangi penyakit TB. Berbagai upaya tersebut telah menunjukkan hasil, penderita penyakit $\mathrm{TB}$ cenderung menurun dari tahun ketahun meskipun dengan pergerakan yang lambat. ${ }^{1}$ Data menunjukkan angka kematian TB telah menurun sebesar $45 \%$ pada tahun 2013 bila dibandingkan pada tahun 1990. ${ }^{1}$ Dalam waktu kurun 13 tahun belakangan ini yaitu tahun 2000 sampai 2013 diperkirakan 37 juta orang berhasil diselamatkan melalui upaya diagnosis dan penalaksanaan yang tepat. ${ }^{1}$ Hal ini memberikan harapan bagi dunia mencapai tujuan penanggulangan penyakit TB dalam Millennium Development Goal (MDG) yang dapat kita lihat pada akhir tahun ini.

Indonesia sebagai negara kelima terbesar di dunia dalam jumlah penderita TB setelah India, Cina, Afrika Selatan dan Nigeria telah berkomitmen mencapai target dunia dalam penanggulangan tuberkulosis. ${ }^{2}$ Strategi DOTS yang direkomendasikan oleh WHO telah diimplementasikan dan diekspansi secara bertahap kepada setiap unit pelayanan kesehatan. ${ }^{2}$ Berbagai kemajuan telah dicapai, namun tantangan program pengendalian $\mathrm{TB}$ pada masa mendatang tetap besar dengan kehadiran TB HIV, TB MDR dan variasinya. $^{2}$

Kehadiran TB MDR tidak lepas dari penanganan TB itu sendiri. Di RS Persahabatan Jakarta, dilaporkan bahwa pengobatan TB-MDR tidak sesuai dengan rejimen, dosis dan lamanya terapi sehingga mempengaruhi angka kesembuhan pasien TBMDR.
Demikian pula monitoring yang dilakukan pada pasien TB-MDR tidak sesuai dengan program yang sudah dilakukan oleh WHO sehingga mempengaruhi penatalaksanaan pasien TB-MDR. ${ }^{3}$

Medan adalah kota yang memiliki kasus terbanyak di Propinsi Sumatera Utara. ${ }^{4}$ Telah dibuktikan terjadi kasus resistensi primer yang tinggi pada penderita TB paru kategori I di Kota Medan sehingga kewaspadaan dan berbagai upaya penanggulangan $\mathrm{TB}$ perlu dilakukan odengan berbagai cara untuk mengurangi kerugian akibat penyakit TB. ${ }^{5}$

Kerugian yang diakibatkan penyakit TB sangat besar, bukan hanya dari aspek kesehatan semata tetapi juga dari aspek sosial maupun ekonomi. ${ }^{6}$ Besar dan luasnya permasalahan akibat TB mengharuskan kepada semua pihak untuk dapat berkomitmen dan bekerjasama dalam melakukan penanggulangan TB. ${ }^{6}$ Dengan demikian TB merupakan ancaman terhadap cita-cita pembangunan nasional Republik Indonesia untuk meningkatkan kesejahteraan rakyat secara menyeluruh. Karenanya perang terhadap TB berarti pula perang terhadap kemiskinan, ketidakproduktifan, dan kelemahan akibat TB. ${ }^{2}$

Mengingat besar dan luasnya masalah TB, maka penanggulangan TB harus dilakukan melalui kemitraan dengan berbagai sektor baik pemerintah, swasta maupun lembaga masyarakat. ${ }^{7} \mathrm{Hal}$ ini sangat penting untuk mendukung keberhasilan program penanggulangan penyakit TB pada masa mendatang. ${ }^{?}$ Tujuan kemitraan untuk pengendalian penyakit TB ini adalah terlaksananya upaya percepatan penanggulangan tuberkulosis secara efektif dan efisien dan berkesinambungan. Hal ini dilakukan dengan cara meningkatkan koordinasi, komunikasi, sumber daya, komitmen, kemampuan dan kekuatan bersama serta membuka peluang untuk saling membantu. ?

Agar tujuan-tujuan tersebut dapat dicapai maka diperlukan prinsip dasar kemitraan, antara lain:

a. Kesetaraan

Bahwa setiap mitra kerja dalam program penanggulangan tuberkulosis patut dihormati dan diberi pengakuan dalam hal kemampuan dan nilai-nilai yang dimiliki mereka serta memberikan kepercayaan penuh kepada masing- 
masing mitra dalam program penanggulangan tuberkulosis.

b. Keterbukaan

Dalamkemitraan harussaling percaya danterbuka dalam pelaksanaan program. Keduabelah pihak harus mempunyai keyakinan bahwa mereka melakukan perjanjian denganterbuka dan jujur dalam pelaksanan program penanggulangan tuberkulosis.

c. Saling menguntungkan

Hubungan kemitraan harus saling menguntungkan masing-masing pihak dalam kerjasama yang dijalin. ${ }^{7}$

Langkah langkah pelaksanaan kemitraan dilakukan dengan cara:

a. Identifikasi, calon mitra yang dianggap potensial untuk menyelesaikan masalah kesehatan yang dihadapi perlu dilakukan identifikasi organisasi dan penjajagan.

b. Sosialisasi tentang program tuberkulosis kepada calon mitra, sehingga mitra bisamemilih peran di keterlibatannya dalam penanggulangan tuberkulosis.

c. Penyamaan persepsi, agar diperoleh pandangan yang sama dalam penanganan masalahyang dihadapi bersama, maka para mitra perlu bertemu untuk saling memahami kedudukan, tugas dan fungsi masing- masing secara terbuka dan kekeluargaan

d. Pembentukan Komitmen. Komitmen masingmasing pihak sangat penting terutama komitmen para pengambil kebijakan sehingga apa yang menjadi kesepakatan dan tujuanbersama dalam tercapai

e. Pengaturan peran. Peran masing-masing sektor dalam penggulangan tuberculosis perlu disepakati bersama, lebih baik secara tertulis jelas yang dituangkan dalam dokumen resmi

f. Komunikasi intensif, untuk menjalin dan mengetahui perkembangan kemitraan dalam melaksanakan program tuberculosis perlu dilakukan komunikasi antar mitra secara teratur dan terjadwal, dan dapat diselesaikan masalah di lapangan secara langsung.

g. Melakukan kegiatan. kegiatan yang disepakati harus dilaksanakan dengan baik sesuai dengan rencana kerja tertulis hasil dari kesepakatan bersama

h. Pemantauan dan penilaian, disepakati sejak awal, bila perlu hasil pemantauan ini dapat untuk penyempurnaan kesepakatan yang telah dibuat.?

Konsep kemitraan dan tindaklanjut kerangka kerja terpadu untuk mempengaruhi dan memberdayakan masyarakat dalam pelaksanaan penaggulangan TB dilakukan melalui Advokasi, Komunikasi dan Mobilisasi Sosial (AKMS) yang dirancang secara sistematis dan dinamis. ${ }^{4}$ Advokasi adalah tindakan untuk mendukung upaya masyarakat mendapatkan berbagai sumber daya. Komunikasi merupakan proses dua arah yang menempatkan partisipasi dan dialog sebagai elemen kunci. Dalam konteks penanggulangan $\mathrm{TB}$, komunikasi diarahkan untuk mendorong lingkungan berkreasi melalui pembuatan strategi dan pemberdayaan. Seluruh kegiatan komunikasi disebarluaskan lewat media dan berbagai saluran. Mobilisasi sosial merupakan proses membangkitkan keinginan masyarakat, secara aktif untuk menanggulangi TB yang menguntungkan masyarakat. ${ }^{?}$

Penggerakan masyarakat dilaksanakan di tingkat paling bawah (akar rumput) dan secara luas berhubungan dengan mobilisasi dan aksi sosial masyarakat. Memperhatikan pemaparan komponen AKMS, masing-masing komponen mempunyai tujuan dan kegiatan spesifik yang dilaksanakan secara terpadu untuk mencapai keberhasilan program penanggulangan $\mathrm{TB}^{?}$

Kecamatan Medan Denai telah menjadi Wilayah Binaan FK UMSU sejak tahun 2014 yang lalu. Berbagai kegiatan dilakukan disana, antara lain pembentukan Forum Masyarakat Peduli Penyakit Tuberkulosis. Forum ini beranggotakan kepala keluarga yang telah ikut serta dalam Program Keluarga Binaan Kesehatan Fakultas Kedokteran Universitas Muhammadiyah Sumatera Utara. Forum ini merupakan wadah para kader kesehatan untuk membantu petugas kesehatan dalam mengatasi persoalan kesehatan masyarakat antara lain TB. Forum ini baru saja terbentuk pada akhir tahun 2014, sehingga anggotanya perlu dilatih agar mampu 
memainkan perannya dalam penanganan penyakit TB.

Tujuan penelitian ini adalah untuk mengetahui efektifitas pelatihan penanganan penyakit TB yang telah diberikan kepada seluruh kader kesehatan.

\section{METODE}

Desain penelitian ini menggunakan one group pre test and post test, para responden mendapatkan satu tes sebelum diberi perlakuan..$^{8-10}$ Variabel bebas dalam penelitian ini adalah keikutsertaan dalam pelatihan dan variabel terikatnya adalah pengetahuan mengenai penanganan penyakit TB. Pengetahuan mengenai penanganan penyakit Tuberkulosis didefinisikan sebagai kemampuan peserta menjawab pertanyaan yang diajukan mengenai definisi, cara penularan, gejala penyakit, faktor risiko menjadi penderita, cara pemeriksaan, cara pengobatan, lama pengobatan, biaya pengobatan, tempat berobat yang tepat dan peran keluarga dalam penanganan penyakit TB.

Populasi dalam penelitian ini adalah seluruh kader kesehatan yang merupakan anggota Forum Masyarakat Peduli Penyakit TB yang dibentuk oleh Fakultas Kedokteran UMSU yaitu sebanyak 50 orang. Kelompok populasi juga merupakan kepala keluarga yang sedang mengikuti Program Keluarga Binaan Kesehatan FK UMSU selama setahun dari dua setengah tahun yang direncanakan. Sampel penelitian diambil dengan metode total sampling yang memenuhi kriteria inklusi. ${ }^{11-13}$ Kriteria inklusi yang ditetapkan yaitu kader kesehatan yang mengikuti acara pelatihan sampai dengan selesai dan mengisi kuesioner pretest dan posttest secara lengkap.Dalam hal ini berarti subjek yang tidak memberikan jawaban secara lengkap, tidak termasuk sebagai sampel. Karena hanya yang lengkap saja yang akan dianalis datanya.

Teknik atau metode dalam pengumpulan data ini dilakukan dengan memberikan lembar isian berupa pilihan A sampai C dengan tingkat kebenaran hampir sama atau mendekati kebenaran. Di sini peserta diberikan lembaran yang harus diisi sesuai dengan yang diketahuinya sebelum adanya pelatihan. Setelah dilakukan pelatihan peserta kembali diberikan lembaran isian yang sama seperti pada saat sebelum diadakannya pelatihan. Didapatlah perbedaan pengetahuan sebelum dan sesudahnya. ${ }^{8,9}$ Pengumpulan data ini dilakukan dengan didampingi dan diawasi oleh mahasiswa FK UMSU yang menjadi anggota petugas pelatihan. Untuk memastikan maksud yang disampaikan dari pertanyaan-pertanyaan tersebut dapat benar-benar dipahami oleh responden. Data hasil jawaban responden atas kuesioner yang diserahkan kepada peneliti diseleksi dan hanya data yang lengkap saja yang dapat diolah menjadi data hasil penelitian. Jawaban responden diukur dengan menggunakan skala likert benar dan salah. Data yang lengkap kemudian di uji normalitas dengan menggunakan uji Kolmogorov-smirnov, selanjutnya bila datanya terdistribusi normal maka dilanjutkan dengan uji statistik inferensial parametrik dengan uji $\mathrm{T}$ test namun apabila data tidak terdistribusi normal maka digunakan statistik inferensial dengan uji Wilcoxon. ${ }^{15}$ Untuk mendapatkan hasil analisis pre and post test tersebut, diperlukan alat bantu analisis data yaitu dengan menggunakan bantuan program perangkat lunak komputer IBM SPSS for Windows version 21.0.

\section{HASIL DAN PEMBAHASAN}

Populasi terdiri dari laki-laki dan perempuan, berasal dari latar belakang yang berbeda. Sebagian dari sampel berprofesi sebagai pedagang, pegawai kelurahan, anggota PKK, dan ibu rumah tangga biasa. Subjek juga terdiri dari berbagai tingkatan usia. Ada yang berkisar 18-23 tahun, 24-29 tahun, 30-35 tahun dan ada juga yang usianya $>35$ tahun.

Hanya 47 orang responden yang mengisi data dengan lengkap. Sehingga data yang dianalisis hanya berjumlah 47 sampel.

Dari uji normalitas didapatkan hasil bahwa data berdistribusi tidak normal sehingga digunakan Uji Wilcoxon. Uji Wilcoxon digunakan untuk menentukan apakah ada perbedaan rata-rata dua sampel yang saling berhubungan. Dalam hal ini sampel tersebut adalah jawaban yang ada di bagian pre and post test tadi. ${ }^{16}$

Dalam uji wilcoxon ini terdapat dua jenis hipotesis, yaitu Ho dan Ha. Dimana Ho diartikan bahwa tidak adanya perbedaan pengetahuan antara sebelum dan 
sesudah pelatihan.Sedangkan Ha diartikan bahwa ada perbedaan pengetahuan antara sebelum dan sesudah dilakukan pelatihan. Dalam pengambilan keputusan, teknik ini mempunyai syarat yaitu apabila Sig > 0,05 maka Ho diterima. Dengan kata lain, tidak ada perbedaan antara sebelum dan sesudah dilakukan pelatihan. Sebaliknya, jika Sig <0,05 maka Ho ditolak. Hal ini berarti ada perbedaan tingkat pengetahuan antara sebelum dan sesudah dilakukan pelatihan. ${ }^{16}$ Hasil uji Wilcoxon dapat dilihat dalam tabel berikut :

Tabel 1. Hasil Analisis menggunakan Uji Wilcoxon

\begin{tabular}{lc}
\multicolumn{1}{c}{ Pretest - Posttest } & n \\
\hline Pengetahuan berkurang & $3(6,4 \%)$ \\
Pengetahuan bertambah & $34(72,3 \%)$ \\
Tidak ada perbedaan & $10(21,3 \%)$ \\
\hline Total & $47(100 \%)$ \\
\hline
\end{tabular}

Tabel 2. Hasil Analisis menggunakan Uji Wilcoxon

\begin{tabular}{ll} 
& sesudah - sebelum \\
\hline$Z$ & $4.837^{\mathrm{b}}$ \\
\hline Asymp. Sig. (2-tailed) & .000 \\
\hline
\end{tabular}

Dari tabel 1 dapat dilihat bahwa peserta yang pengetahuannya mengalami penurunan sebelum dan sesudah dilakukannya pelatihan ada 3 orang. Sedangkan peserta yang pengetahuannya bertambah berjumlah 34 orang. Dan peserta pelatihan yang pengetahuannya sama antara sebelum dan sesudah dilakukannya pelatihan sebanyak 10 orang.

Tabel 2 menjelaskan tentang hasil uji statistik. Dimana hasil Sig $=0,000$ dengan based on negative ranks sebesar $-4,837$. Hasil analisis menyatakan jumlah Sig < 0,05 . Hal ini menunjukkan bahwa terjadi perbedaan tingkat pengetahuan dan penanganan terhadap penyakit tuberkulosis antara sebelum dan sesudah dilakukannya pelatihan penyakit tuberculosis di wilayah kerja keluarga binaan Fakultas Kedokteran Universitas Muhammadiyah Sumatera Utara.

Dari tabel 3 di bawah tampak bahwa peningkatan pengetahuan kader Posyandu sebelum dan sesudah diberi pelatihan yang paling besar terjadi pada $\mathrm{p} 9$ yaitu berkaitan dengan biaya pengobatan TB (terjadi peningkatan 38,3\%). Kemudian diikuti dengan p11 yaitu tentang peran keluarga terhadap pengobatan TB (terjadi peningkatan 25,53\%).

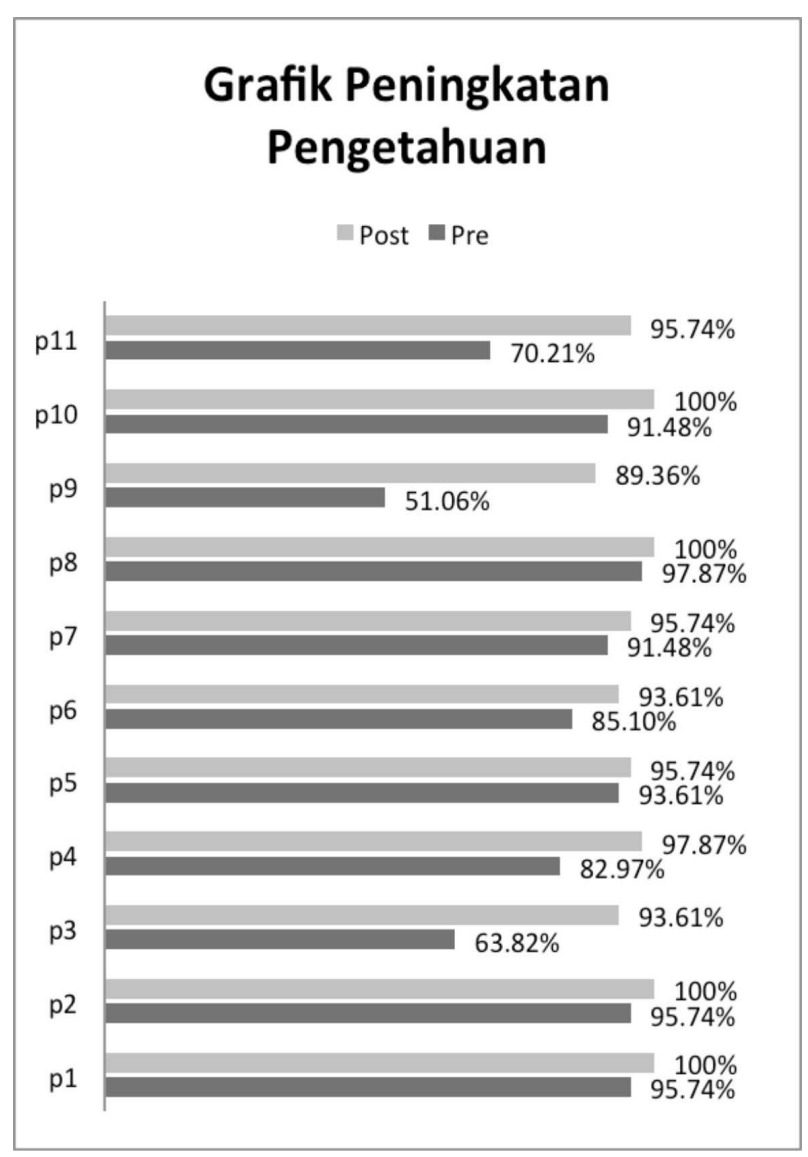

Gambar 1. Grafik gambaran peningkatan pengetahuan

Keterangan :

$\mathrm{p} 1=$ Apa defenisi TB, $\mathrm{p} 2$ = Bagaimana Cara TB ditularkan, p3 = Apa gejala utama TB, p4 = Apa gejala tambahan TB, p5 $=$ Faktor resiko TB, p6 $=$ Cara Pemeriksaan TB yang benar, $\mathrm{p} 7=$ Cara Mengobati $\mathrm{TB}$ yang benar, $\mathrm{p} 8=$ Lama pengobatan $\mathrm{TB}, \mathrm{p} 9=$ Berapa biaya pengobatan $\mathrm{TB}, \mathrm{p} 10=$ Dimana tempat berobat, $\mathrm{p} 11=$ Bagaimana Peran keluarga terhadap pengobatan $\mathrm{TB}$.

Hasil analisis data penelitian menunjukkan perubahan yang signifikan terhadap perbedaan tingkat pengetahuan kader terhadap penanganan penyakit tuberculosis antara sebelum dan sesudah dilakukannya pelatihan. Sebagian besar peserta latih yaitu sebanyak 34 dari 47 orang atau sebesar $72 \%$ pengetahuannya bertambah setelah diberikan pelatihan. Hasil analisis statistik menunjukkan bahwa terjadi perbedaan 
tingkat pengetahuan dan penanganan terhadap penyakit tuberkulosis antara sebelum dan sesudah dilakukannya pelatihan penyakit tuberculosis di wilayah kerja keluarga binaan Fakultas Kedokteran Universitas Muhammadiyah Sumatera Utara.

Hal ini sejalan dengan penelitian yang dilakukan oleh Murti ${ }^{17}$ yang menunjukkan bahwa pengetahuan kader kesehatan tuberkulosis dalam wadah dasawisma meningkat setelah diberikan pelatihan. Hanya saja penelitian ini membandingkan antara efektifitas pelaku pelatihnya, yaitu tenaga medis dan peer educator. Hasilnya menunjukkan bahwa pelatihan yang dilakukan oleh peer educator lebih signifikan meningkatkan kemampuan kader kesehatan dalam mencari kasus baru TB. Karakteristik populasi penelitian sama dengan penelitian yakni berdasarkan rentang usia yaitu 25-50 tahun dan rentang pendidikan dari SD sampai dengan SMA.

Penelitian yang dilakukan Sabri(2009), menunjukkan pula bahwa pelatihan untuk meningkatkan pengetahuan kader kesehatan penting dilakukan. Sabri meneliti ibu-ibu kader kesehatan yang menjadi Pengawas Menelan Obat (PMO) di Padang dan membandingkan tingkat pengetahuan peserta latih sebelum dan sesudah dilakukan pelatihan. Sabri juga merekomendasikan perlunya buku modul pelatihan TB bagi kader kesehatan agar pengetahuan peserta latih meningkat lebih baik lagi. ${ }^{18}$

Peningkatan pengetahuan kader kesehatan mengenai biaya berobat TB sangat penting artinya bagi pencegahan angka drop out penderita $\mathrm{TB}$ dalam mengkomsi obat. Hal ini seperti yang disebutkan oleh hasil penelitian Nugroho ${ }^{18}$ bahwa salah satu faktor penentu drop out dari pengobatan TB adalah pasien merasa sembuh, biaya pengobatan yang tidak gratis dan ketiadaan pengawas menelan obat (PMO).

\section{KESIMPULAN}

Pelatihan peningkatan pengetahuan tentang penanganan penyakit $\mathrm{TB}$ efektif meningkatkan pengetahuan kader kesehatan di wilayah kerja keluarga binaan FK UMSU. Modul penelitian perlu dipersiapkan dengan lebih baik untuk dibaca dan dipelajari oleh para kader kesehatan.

\section{SARAN}

Untuk meningkatkan manfaat pelatihan ini, sebaiknya pelatihan seperti ini dapat dilakukan secara kontinu untuk menambah pengetahuan warga binaan. Tidak hanya penyakit tuberkulosis, tetapi juga berbagai macam masalah kesehatan lainnya. Peer educator dapat dilibatkan sebagai bagian dari pelatih dalam pelatihan untuk meningkatkan pengetahuan kader kesehatan dan memperluas jaringan pelatihan.

\section{DAFTAR PUSTAKA}

1. WHO. Factsheet on TB. 2015 available from: $<\underline{\mathrm{Http}: / /}$ Www. Who.Int/> [Accessed 25 February 2015]

2. Departemen Kesehatan RI. Pedoman Nasional Penanggulangan Tuberkulosis Edisi Kedua Cetakan Pertama. Depkes RI; 2006.

3. Munir, Melati S, Nawas A, Soetoyo DK,.Pengamatan Pasien Tuberkulosis Paru dengan Multidrug Resistant (TB-MDR) di Poliklinik Paru RSUP Persahabatan. Populasi; 2008.

4. Zuliana, Imelda. Pengaruh Karakteristik Individu, Faktor Pelayanan Kesehatan dan Faktor Peran Pengawas Menelan Obat terhadap Tingkat Kepatuhan Penderita TB Paru dalam Pengobatan di Puskesmas Pekan Labuhan Kota Medan Tahun 2009; 2010.

5. Sihombing, Hendra. Pola Resistensi Primer pada Penderita TB Paru Kategori I di RSUP H. Adam Malik, Medan. Online J Respir Indo. 2012; 32:138. 45.

6. Departemen Kesehatan RI. Pedoman Nasional Penanggulangan Tuberkulosis Edisi Kedua Cetakan Pertama.Bab 8 Kemitraan Dalam Penanggulangan Tuberkulosis. Depkes RI. 2006, 61-2.

7. Departemen Kesehatan RI. Pedoman Nasional Penanggulangan Tuberkulosis Edisi Kedua Cetakan Pertama.Bab 9. Advokasi, Komunikasi dan Mobilisasi Sosial (AKMS) Penanggulangan Tuberkulosis. Depkes RI. 2006, 63-9.

8. Fraenkel, Jack R, Norman EW,. How To Design And Evaluate Research In Education. Vol. 7. New York: Mcgraw-Hill; 1993.

9. Dugard, Pat, John T,.Analysis of Pre-Test Post-Test Control Group Designs in Educational Research. Educational Psychology 15.2 (1995): 181-98.

10. Dimitrov, Dimiter M, Phillip DR,.Pretest-Posttest Designs and Measurement of Change. Work:A Journal of Prevention, Assessment And Rehabilitation 20.2 (2003); 159-165. 
11. Esbensen, Kim H. Representative Process Sampling in Practice: Variographic Analysis and Estimation of Total Sampling Errors (TSE). Chemometrics And Intelligent Laboratory Systems 88.1 (2007); 41-59.

12. Arikunto S. Prosedur Penelitian Suatu Pendekatan Praktik. Jakarta: Asdi Mahasatya; 2006.

13. Sastroasmoro S, Sofyan I. Dasar-Dasar Metode Penelitian Klinis Edisi 3. Jakarta: Sagung Seto; 2008.

14. Jamieson, Susan. Likert Scales: How To (Ab) Use Them. Medical Education 38.12 (2004); 1217-8.

15. Myoung PH. Univariate Analysis and Normality Test Using SAS, Stata, AndSPSS.The University Information
Technology Services, Indiana University. Recuperado El 25; 2008)

16. Sopiyudin DM. Statistik untuk Kedokteran dan Kesehatan. Jakarta: Penerbit Salemba; 2011.

17. Murti SE, Prabandari SY, Riyanto SB. Efektifitas Promosi Kesehatan Dengan Peer Education pada Kelompok Dasawisma dalam Upaya Penemuan Tersangka TB Paru. 2006: Berita Kedokteran Masyarakat; 22.3 (2015).

18. Nugroho AR. Studi Kualitatif Faktor yang Melatar Belakangi Drop Out Pengobatan Tuberkulosis Paru. Jurnal Kesehatan Masyarakat 7.1 (2011): 83-90. 